\title{
CONTROLE DE EMISSÃO DE COMPOSTOS ORGÂNICOS COM BASE NO POTENCIAL DE FORMAÇÃO DE OZÔNIO
}

\author{
Gabriel Murgel Branco ${ }^{a}$ \\ Alfred Szwarc ${ }^{b}$ \\ Fábio Cardinale Branco ${ }^{\mathrm{C}}$ \\ Francisco Emílio B. Nigro $^{d}$ \\ RESUMO \\ O controle da emissão de compostos orgânicos no gás de escapamento de veículos automotores \\ leves é atualmente referenciado na emissão de hidrocarbonetos "não metano" (NMHC), sem que haja \\ distinção dos diversos compostos que compõe esse tipo de emissão. No caso dos veículos flex, \\ quando esses veículos operam exclusivamente com etanol, é permitido o desconto da parcela de \\ etanol presente nessa emissão. Essa permissão, que foi concedida inicialmente para facilitar o \\ desenvolvimento da primeira geração de motores flex, mas que ainda está em vigor, foi baseada na \\ premissa de que a emissão de etanol é menos impactante no meio ambiente e é gerada nos poucos \\ minutos que seguem a partida a frio do motor, quando o conversor catalítico ainda não atingiu a sua \\ temperatura de trabalho.
}

Sem a limitação da emissão de etanol não queimado, as preocupações com o seu controle perderam prioridade e isso resultou na produção de diversos modelos de veículos que apresentam essa emissão em níveis mais elevados do que poderia ser atingido. Embora a reatividade atmosférica do etanol seja relativamente baixa em comparação com grande parte dos hidrocarbonetos gerados pela queima da gasolina, o aumento dessa emissão colocou uma parcela relevante da frota flex como capaz de apresentar maior risco de contribuição para a formação de ozônio troposférico do que os demais veículos de mesmo tipo.

Este trabalho apresenta os princípios propostos para a correção dessa anomalia, embasados no preceito de que o "desconto do etanol" deixa de ser total para ser considerado proporcionalmente à sua reatividade na atmosfera, isto é, ao seu potencial de formação de ozônio. Conceitualmente, tratase de converter cada classe de compostos orgânicos, através das respectivas reatividades, em "potencial de ozônio", e ponderar os seus efeitos numa base comum, para expressá-los como "hidrocarboneto equivalente", cujos resultados podem ser comparados aos valores internacionais relativos à gasolina e ao óleo diesel.

\section{EMISSION CONTROL OF ORGANIC COMPOUNDS BASED ON THE OZONE-FORMING POTENTIAL}

\begin{abstract}
The control of exhaust organic compounds emission is presently based on the emission of nonmethane hydrocarbons, with no compounds speciation. When flex fuel vehicles are fueled with ethanol there is also the discount of unburned ethanol from the total hydrocarbons. This waiver, granted initially to help the development of the first generation of flex fuel vehicles, is still in place and has been adopted based on the assumption that ethanol is less impacting on the environment and it is generated during the few minutes that follow cold engine start when the catalytic converter has not reached its operating temperature.
\end{abstract}

With no limitation of the unburned ethanol emission, control efforts to reduce it lost priority and this has resulted in the production of various models of flex fuel vehicles with higher levels than could be

\footnotetext{
${ }^{a}$ EnvironMentality - Consultor

${ }^{\mathrm{b}}$ ADS - Consultor

${ }^{\mathrm{c}}$ EnvironMentality - Consultor

${ }^{\mathrm{d} E s c o l a}$ Politécnica - USP
} 
achieved. Although ethanol's atmospheric reactivity is relatively low as compared to many hydrocarbons generated from gasoline combustion, the increase of this emission leaves a considerable part of the flex fuel fleet in the position of having a greater potential to contribute to ozone formation than other vehicles of its kind.

This paper presents the proposed principles for correction of this abnormality based on the approach that the "ethanol discount" should be considered in proportion to its reactivity in the atmosphere, i.e. the potential for ozone formation. Conceptually, the goal is to convert each class of organic compounds, by taking into account their reactivity, in "ozone formation potential", and to consider their effects in a common basis to be expressed as "equivalent hydrocarbon", whose results could be compared to international values based on gasoline and diesel.

\section{Introdução}

O PROCONVE - Programa de Controle de Poluição do Ar por Veículos Automotores foi criado pelo CONAMA em 1986 e estabeleceu metas audaciosas de redução da emissão de poluentes, que levaram à modernização tecnológica dos veículos brasileiros. Uma das preocupações naquela época era a de não prejudicar o desenvolvimento do motor a álcool, que estava se consolidando no mercado e era vital como um instrumento da política energética nacional e uma nova tecnologia para reduzir a emissão de poluentes atmosféricos, principalmentemonóxidode carbono (CO).

Entretanto, a emissão decombustível não queimado do motor a álcoolera mais alta do que nos motores a gasolina embora a sua toxicidade e reatividadena atmosfera fossem bem menores. Por uma questão de ordem prática, essa emissão passou a ser medida como hidrocarbonetos totais (THC)apesar do detector de ionização de chama, utilizado para a medição dos hidrocarbonetos, apresentar um fator de sensibilidade inferior para o etanol (a concentração medida de etanol é menor e a massa calculada como se fosse $\mathrm{HC}$ resulta $53 \%$ menor do que a massa real). Diante das informações conhecidas à época e considerando que o PROCONVE teria uma trajetória de longo prazo até atingir seus objetivos ambientais, decidiu-seconsiderar as emissões de compostos orgânicos do motor a álcool como se fossem THC, medidas da mesma forma como no motor a gasolina e sem correção, até que novas pesquisas aprimorassem o tratamento dessa questão.

Mais tarde, em 2003, nasceu o motor flex que, na sua primeira geração, enfrentava dificuldades para manter a emissão de THC dentro dos novos limites de emissão, agora muito mais restritivos. Considerando que essa dificuldade era devida à emissão de etanol durante a partida a frio, resultante da baixa volatilidade do combustível, o IBAMA autorizou o desconto da emissão deálcool não queimado da emissão de hidrocarbonetos não-metano, conforme estabelecido no artigo 6o da Instrução Normativa IBAMA № 54/2004, até que novas tecnologias surgissem para reduzir esta emissão.

Contudo, esta autorização abriu, inadvertidamente, uma brecha na legislação ambientalque incentivou a eliminação da injeção de gasolina na partida a frio em alguns motores, em favor da utilização de etanol em maior quantidade, uma vez que 
esta substânciadeixou de serconsiderada na emissão de combustível não queimado. Essa prática permitiu queesses motores viessem a emitir etanol em quantidades muito superiores à massa de hidrocarbonetos, o que poderia produzir efeitos ambientais equivalentes, recomendando, portanto,que essa anormalidade seja corrigida.

Estudos realizados pelo Instituto Astronômico e Geofísico da USP- IAG ${ }^{1}$ mostram que a formação de ozônio na Região Metropolitana de São Paulo - RMSP é inicialmente dependente da presença de compostos orgânicos voláteis - COV na atmosfera.Portanto, para poder reverter as tendências de aumento da poluição causada pelo ozônio troposférico nessa região e em outras áreas urbanizadas do país que apresentam características similares, é necessário um controle mais severo de todos os compostos orgânicos emitidos, inclusive o etanol.É importante esclarecer que esses fatos não condenam o uso do etanol e tampouco lhe imputam responsabilidade pelapoluição por ozônio. Pelo contrário, como se sabe, esse combustívelapresenta diversos benefícios ambientais e, por conseguinte, o desconto do etanol não queimado é uma prática que deve ser equacionada para consagrar o veículo flex definitivamente como uma alternativa energética limpa.

\section{Caracterização da emissão de compostos orgânicos pelo escapamento}

$O$ detector de ionização de chama (FID) foi escolhido para a medição de THC porque a sua resposta é proporcional ao número de átomos de carbono, independentemente do tipo de hidrocarboneto que está sendo medido. Entretanto, com o uso de compostos oxigenados nos combustíveis, surge a dificuldade deste detector perder esta linearidade por influência do átomo de oxigênio na sua resposta. No caso do etanol, a medição por FID "enxerga" apenas $47 \%$ da massa real existente na emissão ( $\left.\mathrm{EtOH}_{\mathrm{FID}}\right)$.

Por isso, a quantificação dos aldeídos e de etanol exige cuidados adicionais, sendo realizada por cromatografia em medições separadas. Como o metano $\left(\mathrm{CH}_{4}\right)$ é menos tóxico e apresenta baixa reatividade na atmosfera, este é também objeto de uma medição dedicada e descontado dos THC, caracterizando os hidrocarbonetos "não metano" (NMHC), que incluem os aldeídos e etanol ainda medidos como se fossem HC.

A Instrução Normativa IBAMA no 54/2004 autoriza o desconto da parcela de etanol lida pelo FID, além do metano, como representado na figura 1. Esta prática levou a resultados surpreendentemente baixos de NMHC, indicando a necessidade de revisão desta medida elevando o IBAMA a solicitar que a Associação Brasileira de Engenharia Automotiva - AEA promovesse a sua discussão. Para issofoi criado um Grupo de Trabalho Especial sobre o desconto do etanol não queimado, coordenado pelo Profo Francisco Nigro (USP),que propôs o estabelecimento de critérios de desconto para o etanol baseados no potencial de formação de ozônio, apresentados conceitualmente e discutidos neste trabalho. 


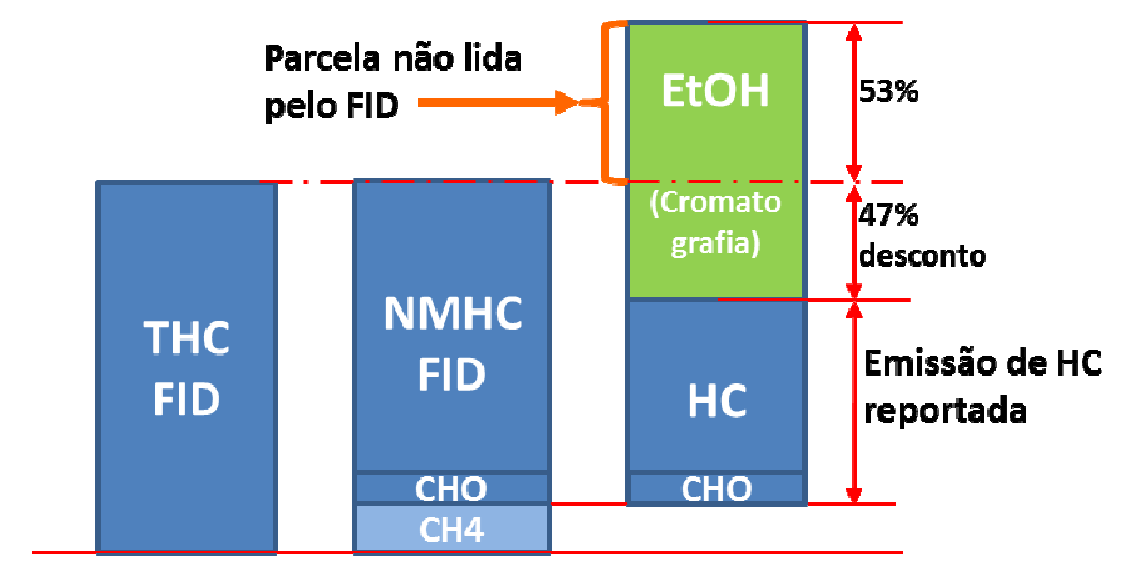

Figura 1 - Representação esquemática dos COV na medição de "HC" atual

\section{Levantamento da emissão de compostos orgânicos em veículos flex}

Com os resultados de 1450 veículos de vários fabricantes, dos quais eram conhecidas as emissões de $\mathrm{THC}, \mathrm{CH}_{4}$ e etanol, em $\mathrm{g} / \mathrm{km}$, foi possível comparar

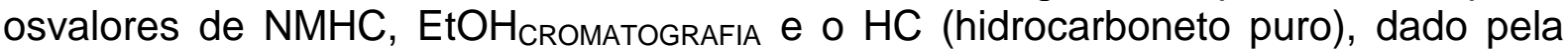

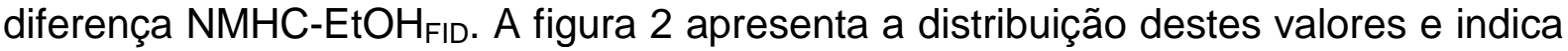
as proporções médias encontradas pelas regressões lineares das mesmas, comparadas aos valores de THC.

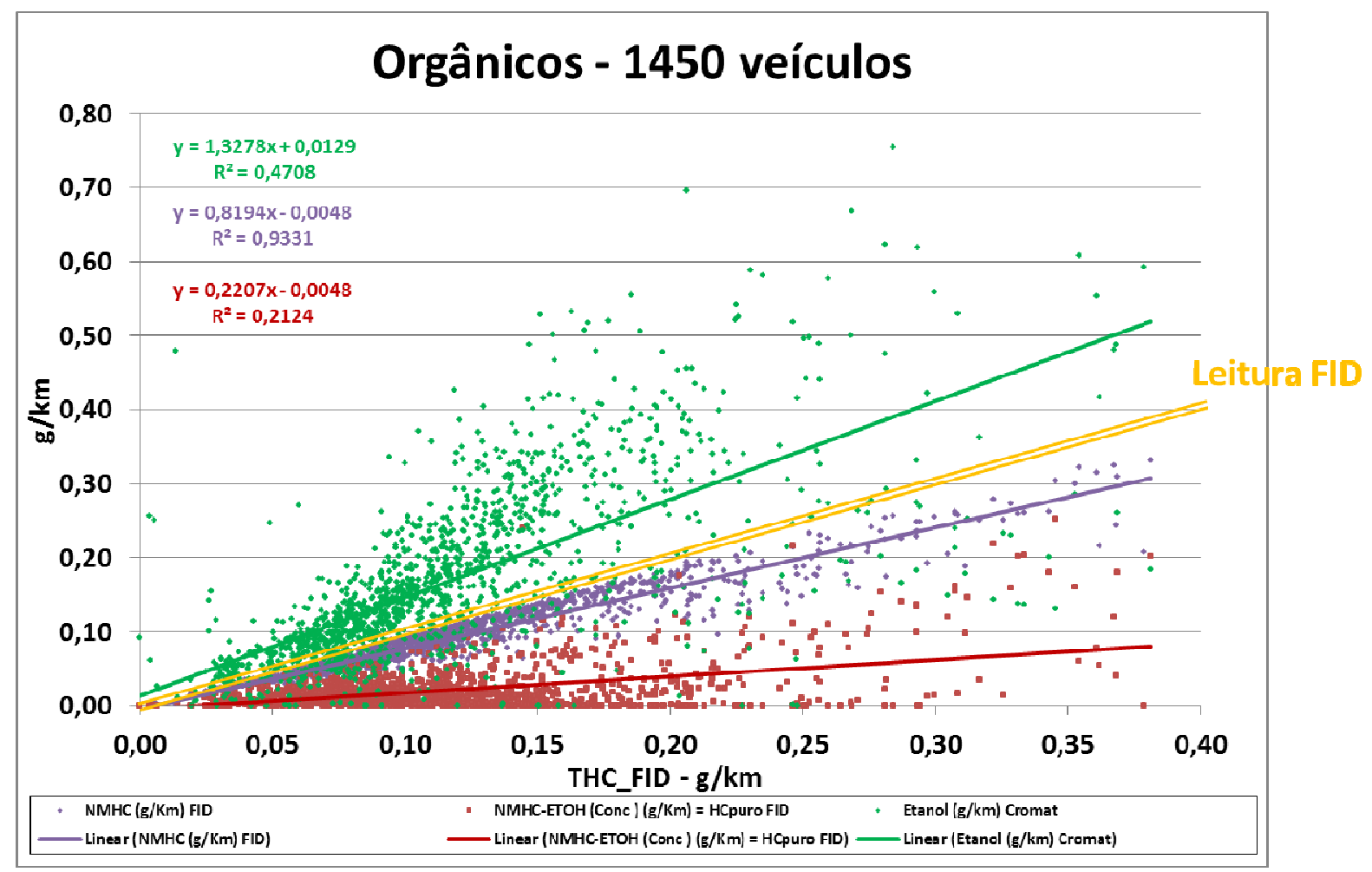

Figura 2 - Comparação das emissões reais de etanol, hidrocarbonetos e NMHC 
Esta figura demonstra que a emissão real de etanol é, em média, cerca de 6 vezes a parcela de hidrocarboneto puro e quase 2 vezes a emissão de orgânicos caracterizada pela medição de NMHC pelo detector FID. Entretanto, sua reatividade é menos da metade da correspondente a estes compostos, o que permite crer que as premissas adotadas no início do PROCONVE, considerando a emissão orgânica do motor a álcool pura e simplesmente como THC, foram adequadas ao desenvolvimento tecnológico da época.

Adistribuição estatística de NMHC desta amostraé semelhanteà dos resultados oficiais de certificação publicados pela ANFAVEA ${ }^{2}$, apresentados na figura 3 . Embora estes permitissem a comparação apenas de NMHC e aldeídos totais, esta comparação atesta a representatividade da amostra.

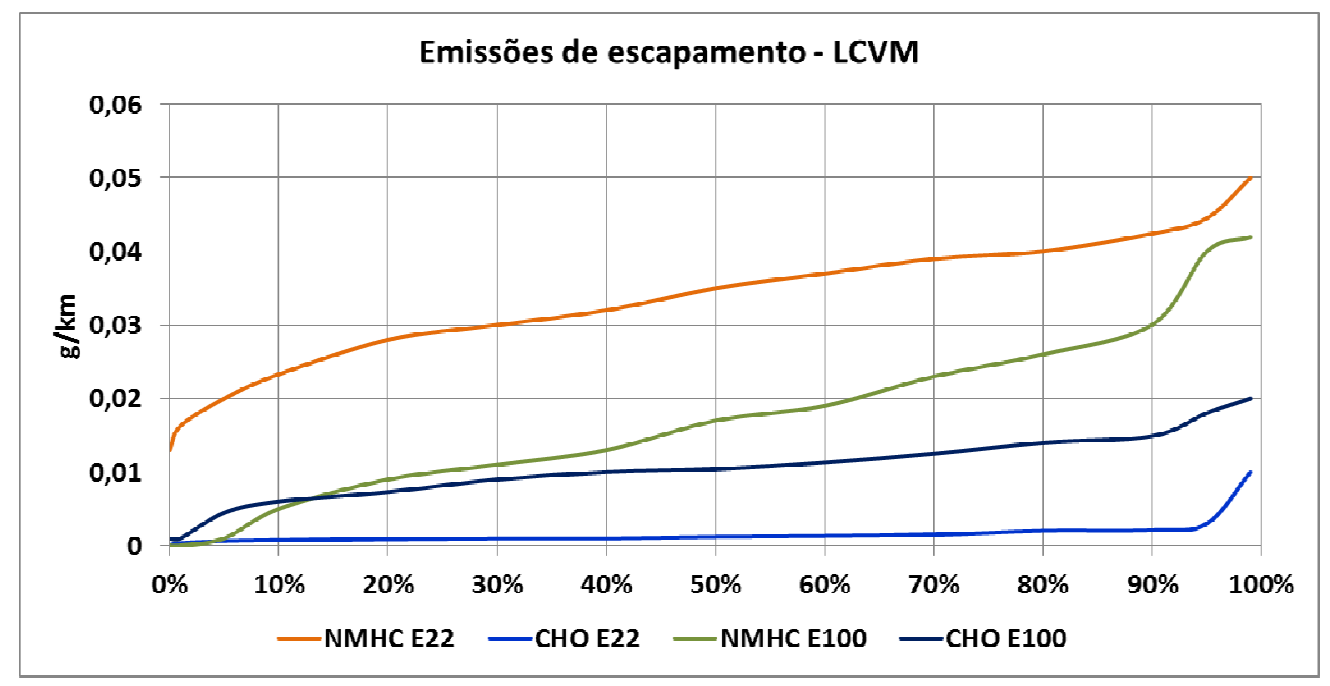

Figura 3 - Distribuições percentílicas das emissões de NMHC e aldeídos totais certificadas em 600 modelos com E22 e E100

Os resultados dos primeiros 1450 veículos permitiram verificar que os diversos parâmetros avaliados apresentam correlação entre si, com exceção da emissão de etanol e HC puro (valor certificado e divulgado), o que desqualifica o parâmetro "NMHC com o desconto do etanol' como representativo desta emissão, como mostra o gráfico da esquerda na figura 4.

Por outro lado, o gráfico da direita mostra que a emissão real de etanol guarda uma boa correlação com a medida simplificada FID (sem correção), o que sugere que a verificação de veículos de produção possa se basear neste método e dispensar as medições por cromatografia (ou parte delas) que são demoradas e caras. O mesmo grau de correlações foi encontrado para os pares $\mathrm{NMHC} / \mathrm{ETOH} \mathrm{F}_{\mathrm{FID}}$ e NMHC/ETOH 

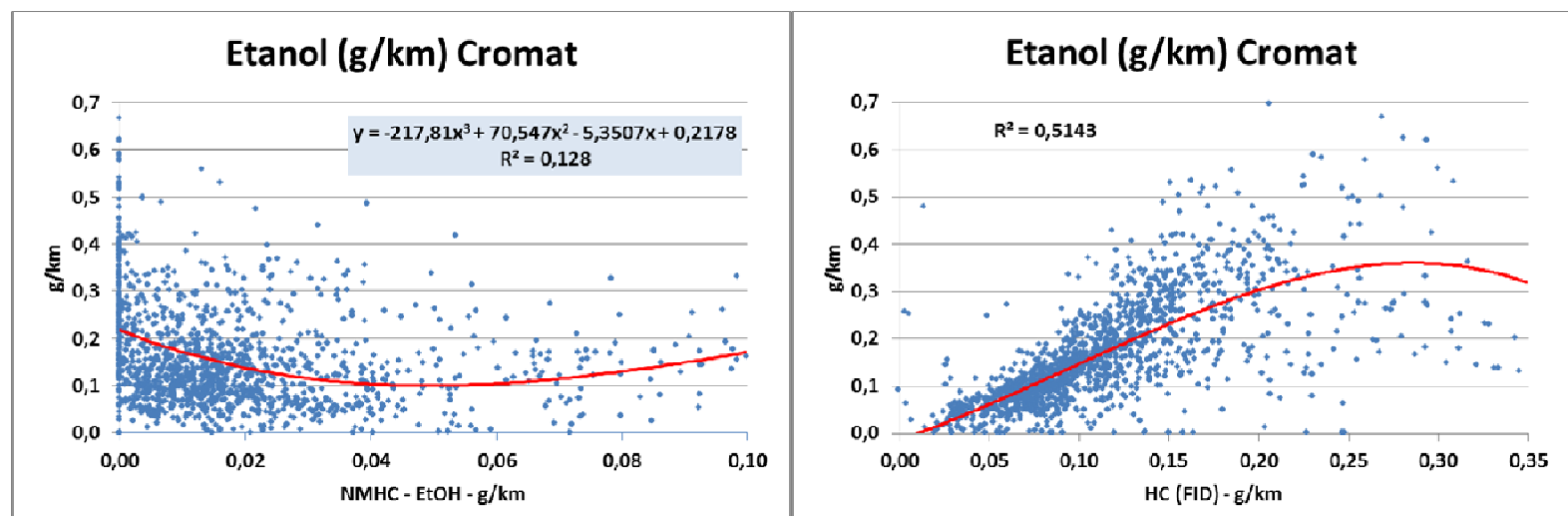

Figura 4 - Correlações entre as emissões de Etanol e Hidrocarbonetos

\section{Análise da especiação dos compostos orgânicos e seus comportamentos}

Como não estavam disponíveis as medições de aldeídos na maioria destas medições, não seria possível fazer uma análise detalhada do potencial de formação de ozônio associado às emissões dos diversos compostos orgânicos presentes nos gases de escapamento dos veículos flex. Esta avaliação foi então procedidacom os ensaios de 40 veículos $^{3}$, entre os quais dispunha-se de 39 resultados medidos com o combustível E22 e 26 com E100.

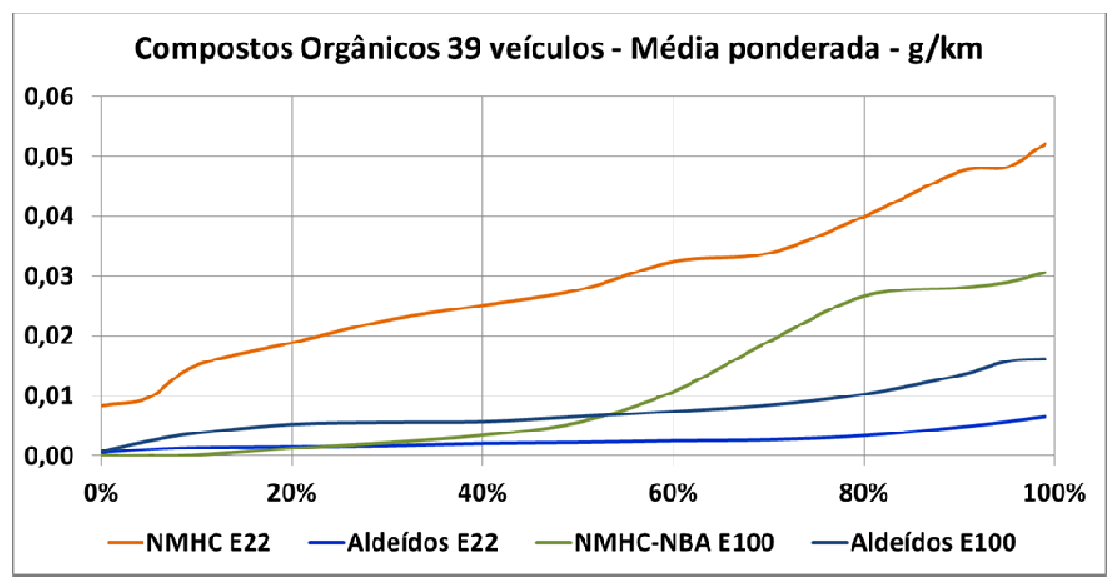

Figura 5 - Distribuições percentílicas das emissões de NMHC e aldeídos totais certificadas em 600 modelos com E22 e E100

Estes dados foram bem mais detalhados, incluindo os valores de aldeídos fórmico e acético separadamente, e também apresentaram distribuições estatísticas de NMHC e aldeídos com boa semelhança aos valores de certificação, apresentados na figura 5 , o que atesta a representatividade desta amostra menor, porém conhecida em mais detalhes e com os dois combustíveis.

Todos os veículos ensaiados com E22 apresentaram emissões de NMHC nas três fases do ensaio, com a média ponderada em conformidade com os limites de HC. Entretanto, os resultados obtidos com E100 mostraram que a emissão de 
$\mathrm{EtOH}$,mesmo sem o desconto permitido, praticamente desaparece nas fases 2 e 3 dos ensaios, mas os seus valores na $1^{\underline{a}}$ fase (com partida a frio) comprometeriam seriamente a conformidade da maioria dos veículos se o etanol não fosse descontado, como mostra a figura 6. Nestes veículos a emissão de hidrocarboneto sem álcool, dada pela diferença entre NMHC e NBA (álcool não queimado, medido pelo FID) também não apresentam boa correlação, confirmando que este parâmetro não representa bem a emissão de compostos orgânicos.

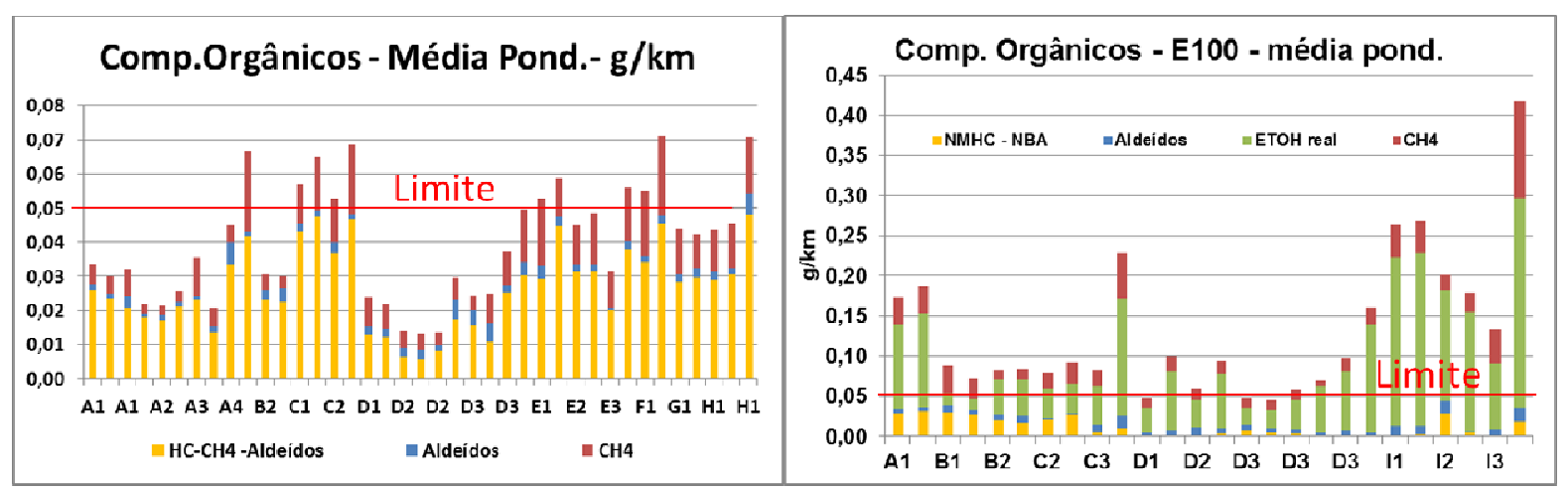

Figura 7 - Comparação das emissões orgânicas de veículos flex

\section{Análise do potencial de formação de ozônio}

A Agência de Proteção Ambiental dos Estados Unidos - EPA define o tratamento das emissões de compostos orgânicos a partir dos seguintes conceitos básicos:

a) NMOG (Non-MethaneOrganic Gases):são todos os hidrocarbonetos não oxigenados que tenham menos de 26 átomos de carbono, com exceção do metano, e todos os aldeídos, cetonas, álcoois e éteres com menos de 6 átomos de carbono, expressos em $\mathrm{g} / \mathrm{km}$, ou seja:

\section{NMOG = THC (non oxig.) $-\mathrm{CH}_{4}+$ Aldeídos + Cetonas + Álcoois}

b) MIR (Máximo Incremento de Reatividade):é o maior incremento da concentração de ozônio atmosférico $\left(\mathrm{O}_{3}\right)$ provocado pela emissão de um composto orgânico, calculado segundo William P. L. Carter (CARB) ${ }^{4}$, expresso em $\mathrm{gO}_{3} / \mathrm{gVOC}$;

c) OFP (Potencial de Formação de Ozônio): é o produto dos valores individuais dos diversos constituintes do NMOG pelos respectivos coeficientes MIR, expressos em gO $/ / \mathrm{km}$;

Com base nestes conceitos os autores propõema definição de "hidrocarboneto equivalente em ozônio" como sendo a emissão em massa de hidrocarbonetos característicos do gás de escapamento de um veículo a gasolina que produzisse a mesma formação de ozônio correspondente aos NMOG sob avaliação ${ }^{\mathrm{e}}$, segundo a equação:

\footnotetext{
"A regulamentação da EPA também define a "Reatividade Específica" (SR) como a média das MIR ponderada pelos NMOG e os "Fatores de Ajuste de Reatividade" (RAF) como o quociente da SR pela MIR do combustível base. Entretanto, estes dois últimos são muito abstratos e enquanto que o conceito de $\mathrm{HC}_{\text {equivalente }}$ demonstra mais claramente os benefícios fisicamente atingidos.
} 


$$
H C_{\text {equiv }}=\frac{\sum N M O G_{i} * M I R_{i}\left(\text { expresso em } g_{O_{3}} / \mathrm{km}\right)}{M I R_{\text {gasolina }}\left(\text { expresso em } g_{O_{3}} / g_{H C}\right)}
$$

Este conceito é o mesmo adotado na regulamentação norte-americana, porém é mais objetivo e permite comparar os impactos sobre a formação de ozônio de um veículo funcionando com etanol e com E22. Este resultado também é comparável com os limites e padrões internacionais de controle da poluição do ar, em termos do seu impacto ambiental, se o parâmetro $\mathrm{MIR}_{\text {gasolina }}$ for determinado no gás de escapamento de um veículo funcionando com gasolina pura ou for calculado a partir da composição deste combustível.

As tabelas dos valores de reatividade são bastante extensas e requerem 0 conhecimento da especiação dos hidrocarbonetos nos gases de escapamento, o que demanda um levantamento trabalhoso e de alto custo. Entretanto, os gases de escapamento de um motor são formados essencialmentepelos mesmos componentes do combustível, exceto pela reatividade diferenciada dos mesmos no conversor catalítico. Por isso, é aceitável adotar uma composição típica como referência, determinada com a gasolina comercial local, ou mesmo a própria composição do combustível, na falta de dados específicos.

As tabelas recomendadas pela EPA apresentam os valores de MIR para cerca de 1400 compostos orgânicos e alguns grupos típicos, tais como olefinas C8, aromáticos $\mathrm{C} 6$ etc., todos representados no gráfico da figura 8 , juntamente com uma curva de regressão que oferece o MIR médio em função do peso molecular do composto.

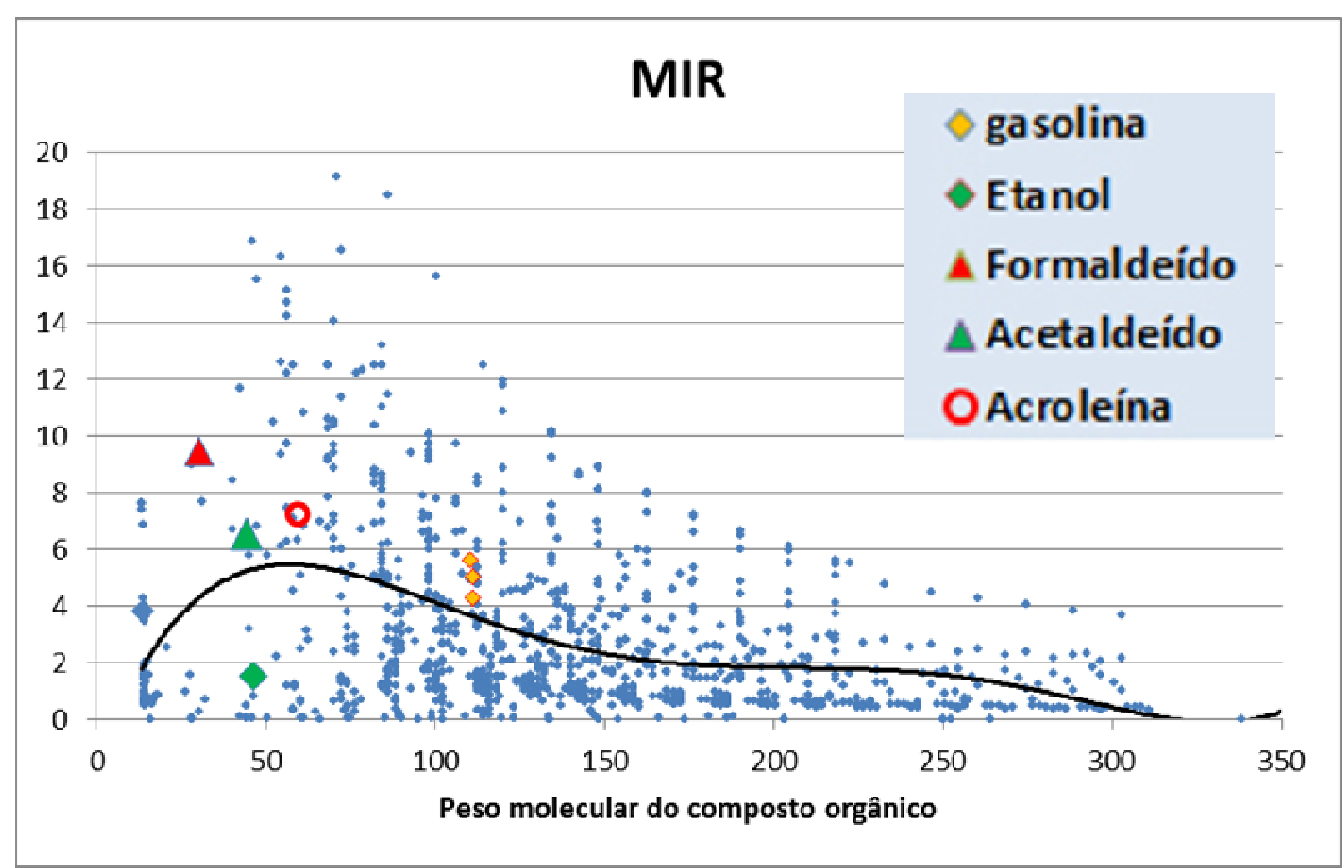

Figura 8 - Distribuição dos valores de MIR, segundo W.P.L. Carter (CARB) 
A título ilustrativo, nesta figura foram destacados os aldeídos fórmico, acético e acroleína, o etanol e a fração de HC da gasolina brasileira, segundo aproximação proposta pelos autores deste trabalho para a comparação dos potenciais de formação de ozônio dos veículos considerados no capítulo 3.

Neste caso, a estimativa da MIR $\mathrm{HC}_{\mathrm{HC}}$ para os hidrocarbonetos da gasolina brasileira isenta de etanol foi feita a partir das percentagens máximas admissíveis de hidrocarbonetos aromáticos, olefínicos e alcanos na gasolina "A", associados aos valores destes grupos de compostos com 6 a 8 átomos de carbono. Esta aproximação foi feita para as especificações da ANP para as gasolinas comercial de 2005, comercial de 2009 e de referência 2009, comparadas com os valores definidos pelo CARB para a gasolina reformulada da Califórnia, como mostrado na tabela 1 , juntamente com os compostos mais relevantes utilizados neste estudo.

Tabela 1 -Reatividade de compostos orgânicos de interesse - W.P.L. Carter

\begin{tabular}{|c|c|c|c|c|c|c|c|}
\hline & Composto & $\begin{array}{c}\text { MIR } \\
\text { gO3/gVOC }\end{array}$ & $\begin{array}{c}\text { Peso } \\
\text { Molecular }\end{array}$ & & Composto & $\begin{array}{c}\text { MIR } \\
\text { gO3/gVOC }\end{array}$ & $\begin{array}{c}\text { Peso } \\
\text { Molecular }\end{array}$ \\
\hline & ETOH & 1,53 & 46 & & acroleína & 7,45 & 56 \\
\hline & Formaldeído & 9,46 & 30,03 & & tolueno & 4,00 & 92 \\
\hline & acetaldeído & 6,54 & 44 & & benzeno & 0,72 & 78 \\
\hline & aldeídos (média & 8 & & & TLEV Exhaust -- RFA & 3,98 & 14,04 \\
\hline & ácido acético & 0,68 & 60 & & TLEV Exhaust -- E-85 & 2,55 & 20,74 \\
\hline & acetona & 0,36 & 58 & & TLEV Exhaust -- CNG & 0,73 & 15,22 \\
\hline & \multicolumn{2}{|c|}{ Fração da Gasolina pura } & & & & & \\
\hline & ANP09_Com & ANP09_Ref & ANP05_Com & CARB & & & \\
\hline arom & $35 \%$ & $35 \%$ & $51 \%$ & $25 \%$ & Aromaticos C8 & 7,64 & 106 \\
\hline olef & $25 \%$ & $15 \%$ & $26 \%$ & $6 \%$ & Olefinas C7-C8 & 5,80 & 112 \\
\hline alcanos & $40 \%$ & $50 \%$ & $23 \%$ & $69 \%$ & Alcanos C6-C8 & 1,44 & 112 \\
\hline MIR & 4,70 & 4,26 & 5,74 & 3,25 & & & \\
\hline
\end{tabular}

Segundo trabalho apresentado pela Petrobrás ${ }^{5}$ no GTE de etanol não queimado, o valor de $\mathrm{MIR}_{\mathrm{HC}}$ medido em gasolinas brasileiras E22, descontados o etanol e os aldeídos, podem variar de 3,08 a 3,71 no ciclo completo da NBR 6601, sendo 4,73 a média na fase com partida a frio. Estes valores devem ser ainda melhor determinados, entretanto, para efeito de avaliação da abordagem aqui proposta, os resultados obtidos nos 40 veículos mencionados no capítulo 3 deste trabalho foram processados com os valores de MIR apresentados na tabela 1, inclusive os dasgasolinas, para comparação e determinação da sensibilidade ao valor de referência que será adotado.

\section{Detalhamento dos cálculos do HC equivalente em ozônio}

$O$ detalhamento do cálculo do $\mathrm{HC}$ equivalente deve ser realizado a partir da equação proposta no apêndice $C$ da norma NBR 6601 para o cálculo do NMHC puro, porém considerando não só o desconto do etanol, mas também dos demais componentes orgânicos dos hidrocarbonetos totais, com aldeídos individualizados. Para o caso do 
etanol, a fórmula completa da NBR 6601 para a determinação do NMHC puro (sem oxigenados) fica então com as seguintes parcelas, como segue:

$T H C=\left[T H C_{e}-T H C_{d}\left(1-\frac{1}{R D}\right)\right]$

$\mathrm{CH}_{4}=\mathrm{Fr}_{\mathrm{CH}_{4}} *\left[\mathrm{CH}_{4_{e}}-\mathrm{CH}_{4_{d}}\left(1-\frac{1}{\mathrm{RD}}\right)\right]$

$\mathrm{ETOH}_{F}=\mathrm{Fr}_{\text {ETOH }} *\left[\mathrm{ETOH}_{C R e}-\mathrm{ETOH}_{C R d}\left(1-\frac{1}{R D}\right)\right]$

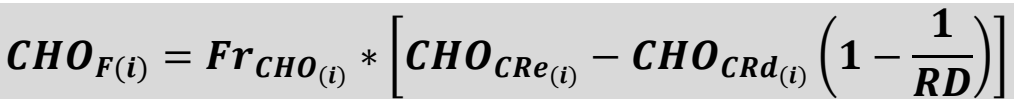

onde:

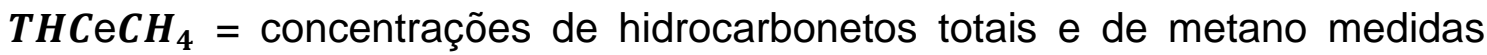
pelo detetor de ionização de chama (FID), expressas em ppmC;

$\boldsymbol{E T O H}_{\boldsymbol{F}}=$ concentração do etanol, referenciada à medição pelo FID, como propano, em ppmC

$\boldsymbol{C H O}_{\boldsymbol{F}(\boldsymbol{i})}=$ concentraçãodacarbonila $_{(\mathrm{i})}$ (aldeídos e cetonas), referenciada à medição pelo FID, como propano, em ppmC

$\boldsymbol{E T O H}_{\boldsymbol{C R} \boldsymbol{e}}-\boldsymbol{E T O H} \boldsymbol{H}_{\boldsymbol{C R d}}=$ concentrações de etanol no gás de escapamento e no ar de diluição, obtidas por cromatografia conforme NBR 15598, expressas em partes por milhão em volume;

$\boldsymbol{C H O}_{\boldsymbol{C R}_{(i)}}-\boldsymbol{C H O}_{\boldsymbol{C R d _ { ( i ) }}}=$ concentrações dacarbonila ${ }_{(\mathrm{i})}$ no gás de escapamento e no ar de diluição, obtidas por cromatografia conforme NBR 12026, expressas em partes por milhão em volume;

e $\quad=$ índice que caracteriza a medição no gás de escapamento

d $\quad=$ índice que caracteriza a medição no ar de diluição

(i) = índice de ordem das carbonilas consideradas;

$\mathrm{Fr}_{\mathrm{x}} \quad$ = fatores de resposta do FID para os compostos orgânicos "X", que converte as concentrações em ppmV para a concentração equivalente de propano, expressa em ppmC,

$\mathrm{RD}=$ razão de diluição da amostragem

As concentrações de álcool, aldeídos e cetonas obtidas por cromatografia são expressas em ppmV e convertidas para as concentrações equivalentes de propano, expressas em ppmC, considerando o fator de resposta Frdo FID para cada composto e o número de átomos de carbono correspondente, para compatibilizá-las coma leitura de THC pelo FID. Desta forma, todas as concentrações podem ser somadas ou subtraídas para a determinação da concentração final de hidrocarbonetos puros (sem compostos oxigenados). Normalmente as carbonilas consideradas nos motores a etanol são o formaldeído e o acetaldeído, mas outras 
carbonilas devem ser consideradas, se forem significativas, e calculadas de maneira semelhante, utilizando-se os respectivos coeficientes indicados na NBR 12026.

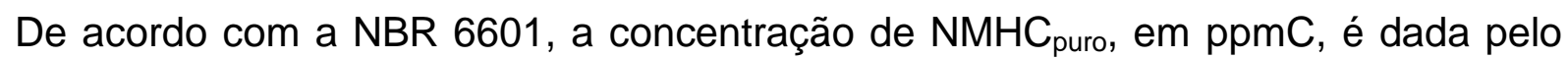
total de hidrocarbonetos (THC), descontadas as frações de metano e de etanol. Entretanto, as frações das carbonilas também devem ser descontadas para que o resultado do NMHC (puro) seja apenas dos hidrocarbonetos:

$$
N M H C_{\text {puro }}=\left(T H C-\mathrm{CH}_{4}-\mathrm{ETOH}_{F}-\sum C H O_{F(i)}\right)
$$

Por serem expressões idênticas, pode-se incluir todas as expressões dos compostos não hidrocarbonetos que são "dedutíveis - CHD" como parcelas de uma mesma somatória para simplificar a expressão:

$$
N M H C_{\text {puro }}=\left(T H C-\sum F r_{C H D_{(i)}} *\left[C H D_{C R e_{(i)}}-C H D_{C R d_{(i)}}\left(1-\frac{1}{R D}\right)\right]\right)
$$

Diante do novo conceito de se regulamentar a emissão de combustível não queimado como "HC equivalente em ozônio" é conveniente estabelecer o cálculo completo e conceitualmente correto.

Também é importante esclarecer que, embora os aldeídos sejam objeto de limites específicos em razão da sua toxicidade, eles também devem ser considerados no cálculo do ozônio para considerar corretamente a sua reatividade atmosférica, por se tratar de efeitos diferentes dos mesmos poluentes sobre o meio ambiente e a saúde. Por isso, o cálculo da massa de $\mathrm{HC}_{\text {equivalentedesconta todos os compostos }}$ orgânicos diferentes de hidrocarbonetos para a determinação da fração de HC "puro".

A partir daíreconsideratodas as frações orgânicas, exceto a do metano cuja reatividade é desprezível, porémcalculadas em massa real e afetadas pela proporcionalidadecom os respectivos fatores de reatividade MIR para a determinação do potencial de formação de ozônio.

As massas de ozônio correspondentes aos compostos orgânicossão calculadas a partir das massas de cada componente, determinadas de acordo com as respectivas normas NBR citadas, conforme as seguintes expressões:

$$
O_{3_{N M H C}}=\frac{v_{e d^{*}} d_{H C}}{10^{6}} N M H C_{\text {puro }} * M I R_{N M H C} \text { Ou }
$$

$$
\begin{aligned}
O_{3_{N M H C}}=\frac{v_{e d} * d_{H C}}{10^{6}} M I R_{N M H C} *\left[T H C_{e}-T H C_{d}\left(1-\frac{1}{R D}\right)\right] \\
-\frac{v_{e d}}{10^{6}} \sum d_{H C} * M I R_{N M H C} * F_{C H D_{(i)}} *\left[C H D_{C R e_{(i)}}-C H D_{C R d_{(i)}}\left(1-\frac{1}{R D}\right)\right]
\end{aligned}
$$

Para os demais componentes "dedutíveis" chamados genericamente de CHD:

$$
\sum o_{3_{C H D_{(i)}}}=\frac{v_{e d}}{10^{6}} * \sum d_{C H D_{(i)}} * \operatorname{MIR}_{C H D_{(i)}} *\left[C H D_{C R e_{(i)}}-C_{C H D_{C R d_{(i)}}}\left(1-\frac{1}{R D}\right)\right]
$$


onde:

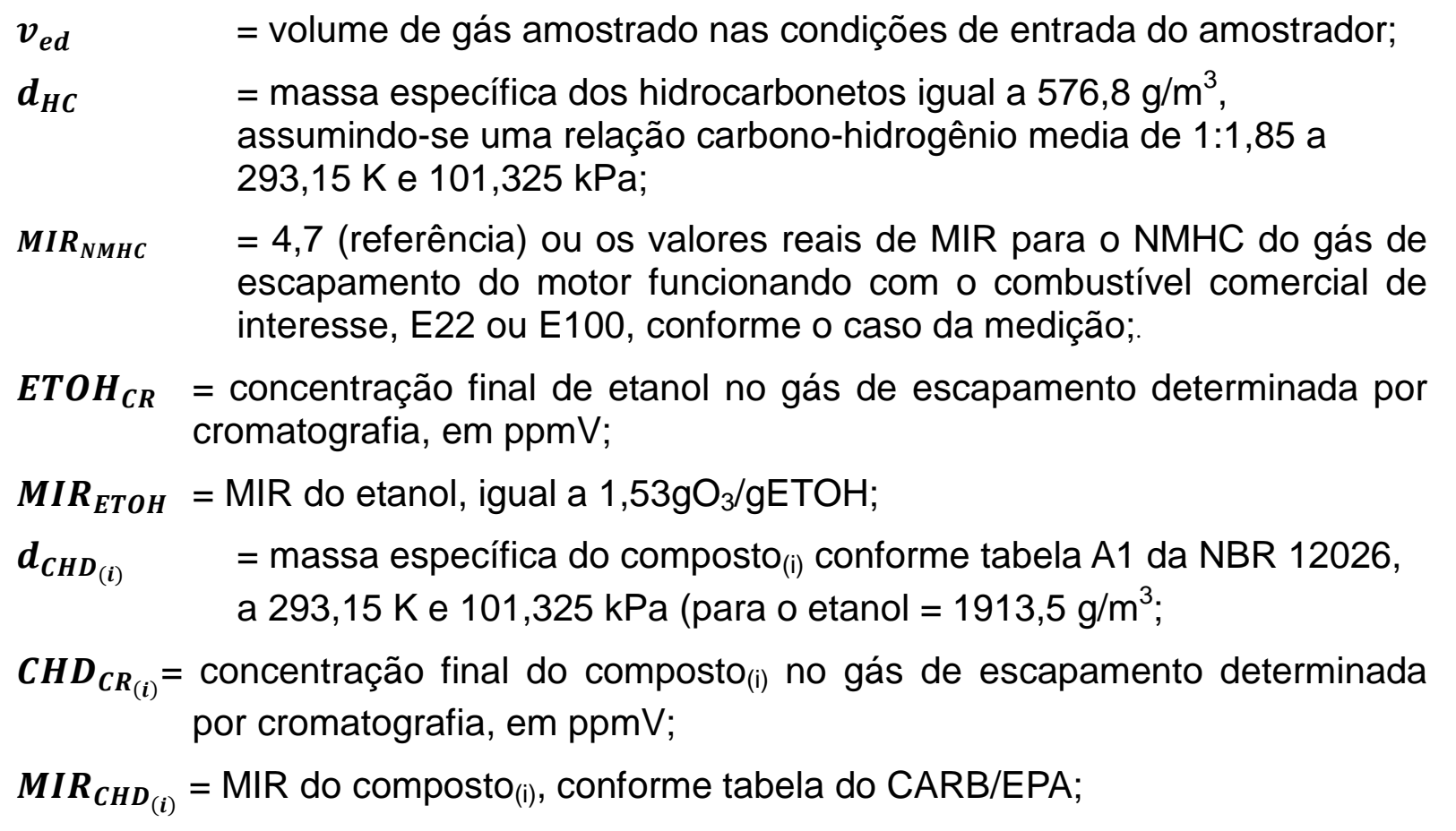

A partir das expressões acima, a somatória das massas de ozônio é dada por:

$$
\begin{aligned}
& O_{3_{\text {TоTAL }}}=\frac{v_{\text {ed }} * \boldsymbol{d}_{H C}}{10^{6}} M^{6} R_{\text {NMHC }} *\left[T H C_{e}-T H C_{d}\left(1-\frac{1}{R D}\right)\right] \\
& +\frac{v_{e d}}{1^{6}} \sum\left[\operatorname{CHD}_{\text {CRe }(i)^{(i)}}-\operatorname{CHD}_{C R d_{(i)}}\left(1-\frac{1}{R D}\right)\right] *\left\{\left(d_{C H D_{(i)}} * \operatorname{MIR}_{C H D_{(i)}}\right)-\left(d_{H C} * M I R_{N M H C} * F_{C H D_{(i)}}\right)\right\}
\end{aligned}
$$

Dividindo-se o potencial de ozônio total pelo MIRNMHC_E22 correspondente aos $\mathrm{NMHC}$ produzidos na queima de gasolina comercialcálculo de $\mathrm{HC}_{\text {equivalente }}$ resulta:

$$
\begin{aligned}
& H C_{\text {equiv }}=\frac{v_{\text {ed }} * d_{H C}}{10^{6}} *\left\{\frac{M I R_{N M H C}}{M I R_{N M H C E 22}} *\left[T H C_{e}-T H C_{d}\left(1-\frac{1}{R D}\right)\right]\right.
\end{aligned}
$$

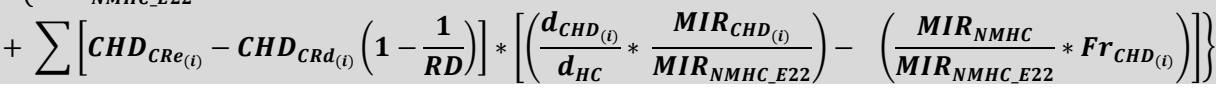

onde:

$\boldsymbol{H C}_{\text {equivalente }}=$ emissão em massa de hidrocarbonetos equivalente

MIR $_{\text {NMHC_E22 }}=4,7$ (referência da gasolina comercial brasileira) ou MIR do $\mathrm{NMHC}_{\text {puro_E22 }}$ de escapamento medido com motores funcionando com gasolina comercial (E22);

Admitindo a simplificação de MIR NMHC_E22 $_{\text {igual a MIR }}$ NMHC_E100, a equação se reduz para: 


$$
\begin{aligned}
& H C_{\text {equiv }}=\frac{v_{e d} * d_{H C}}{10^{6}} *\left\{\left[T H C_{e}-T H C_{d}\left(1-\frac{1}{R D}\right)\right]-\sum F_{C H D_{(i)}} *\left[C H D_{C R e_{(i)}}-C_{C H D_{C R d_{(i)}}}\left(1-\frac{1}{R D}\right)\right]\right\} \\
& +\frac{v_{e d}}{10^{6}} \sum \frac{M^{2} R_{C H D_{(i)}}}{\operatorname{MIR}_{N M H C_{E 22}}} * d_{C H D_{(i)}} *\left[C H D_{C R e_{(i)}}-C_{C H D_{C R d_{(i)}}}\left(1-\frac{1}{R D}\right)\right]
\end{aligned}
$$

As duas primeiras parcelas da equação (linha superior) constituem a equação completa do item C3 do anexo da NBR 6601, enquanto que a terceira parcela (linha inferior) é a correção a ser feita para o cálculo de

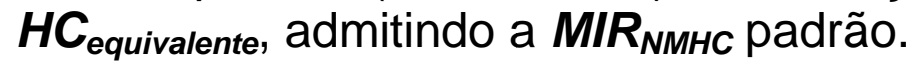

\section{Aplicação experimental do conceito aos veículos flex brasileiros}

Por motivos didáticos, a figura 9 apresenta os resultados para o potencial de ozônio, calculados com o valor de $\mathrm{MIR}_{\mathrm{NMHC}}$ igual a 4,7. Devido ao exagerado desconto do etanol, os resultados de "HC puro"reduziram-se a um resíduo do cálculo comparável à incerteza das medições e alguns tornaram-se negativos, evidenciando outro aspecto a ser corrigido, sendo expurgados nos gráficos seguintes.
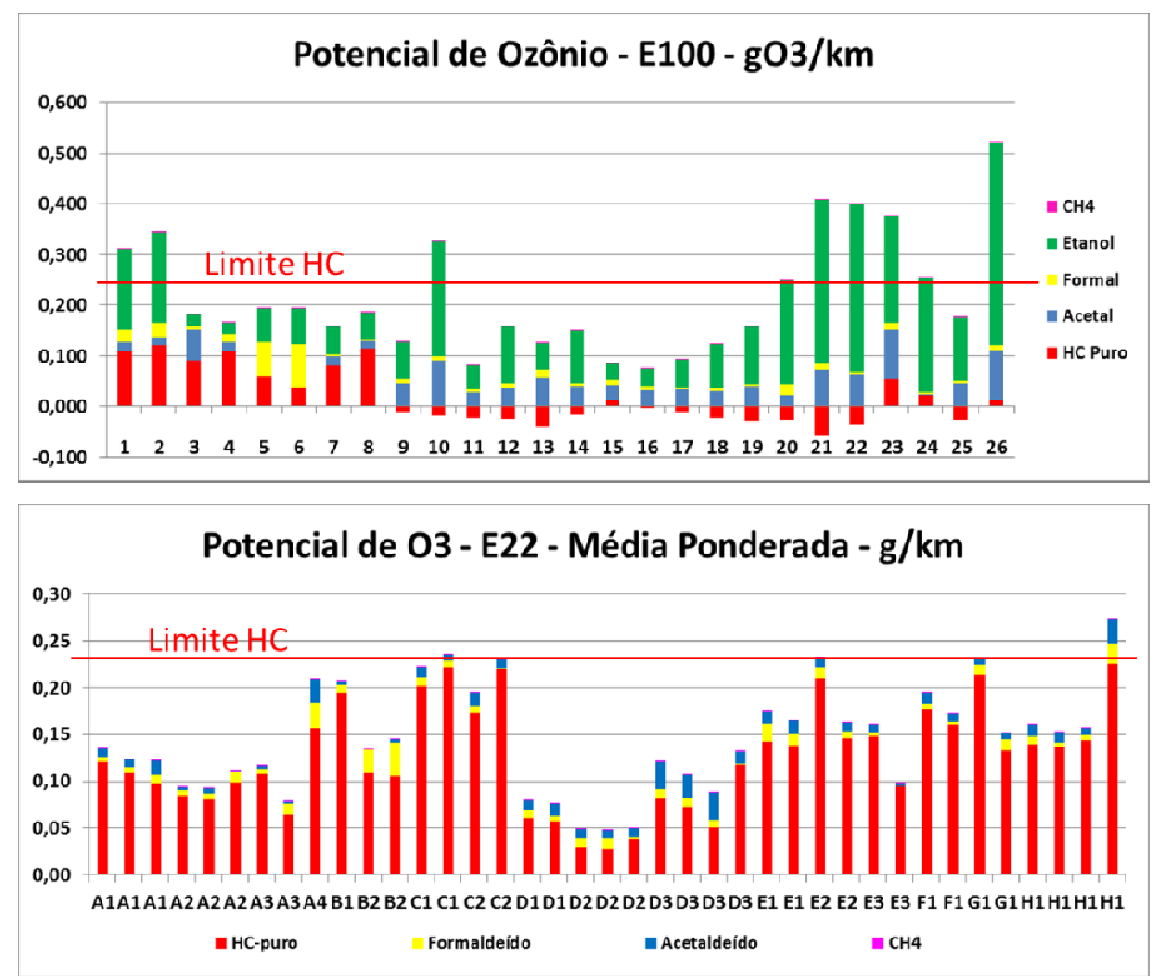

Figura 9 - Resultados individuais do potencial de ozônio $\left(\mathbf{M I R}_{\text {gasolina }}=4,7\right)$

Comparando-se as curvas percentílicas da distribuição estatística da amostragem de resultados dos 40 veículos avaliados para este trabalho, verifica-se que,em cerca de $30 \%$ deles, quando funcionam com E100,a emissão de etanol os levaria à desconformidade com o potencial de ozônio correspondente ao limite de HC, enquanto que com E22 isto não acontece. 


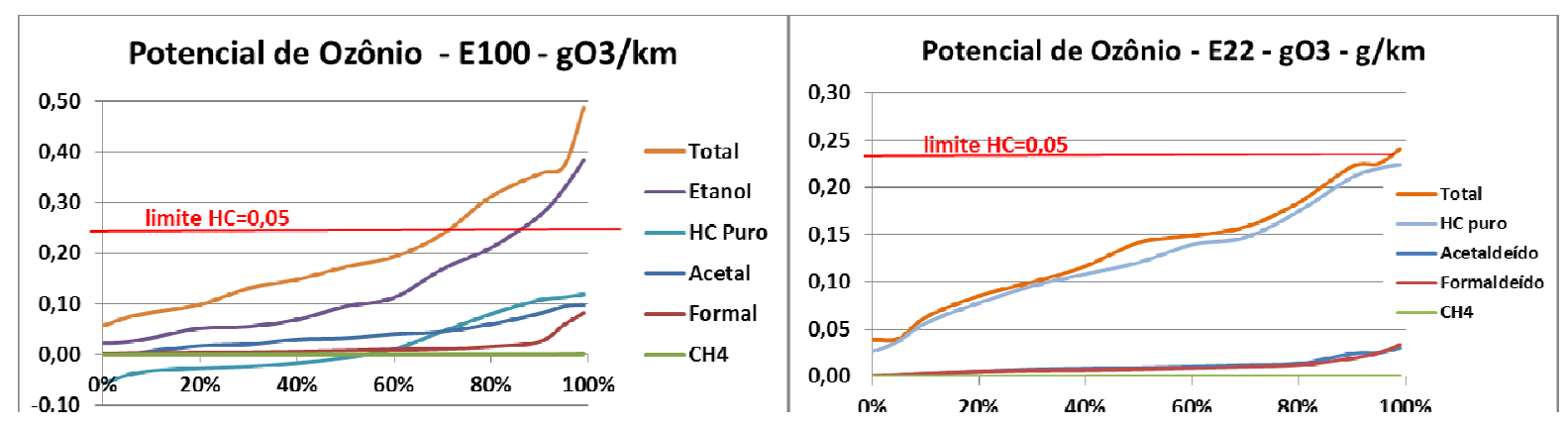

Figura 10 - Resultados estatísticos do potencial de ozônio $\left(\mathbf{M I R}_{\text {gasolina }}=4,7\right)$

Para avaliar a sensibilidade dos resultados comparativos em relação ao valor a ser adotado para o parâmetro $\mathrm{MIR}_{\mathrm{NMHC}}$, os mesmos resultados dos ensaios foram recalculados para os valores estimados para as diversasgasolinas e assumindo-se que os NMHC gerados com E22 e E100 fossem iguais. Neste caso, somente com valores muito altos e improváveis para a gasolina brasileira comercial atual, a desconformidade dos veículos com o potencial de formação de ozônio não seria verificada nos casos de alta emissão de etanol, como mostrado nos gráficos da figura 11, pois a diferença entre os impactos na formação de ozônio deixaria de existir se o valor de MIR ${ }_{\mathrm{NMHC}}$ se aproximasse de 8,0 o que é visivelmente impossível. Inversamente, se a gasolina brasileira tiver a qualidade da existente na California, quase $45 \%$ dos motores deveriam sofrer alterações para igualarem seus resultados com os dois combustíveis.

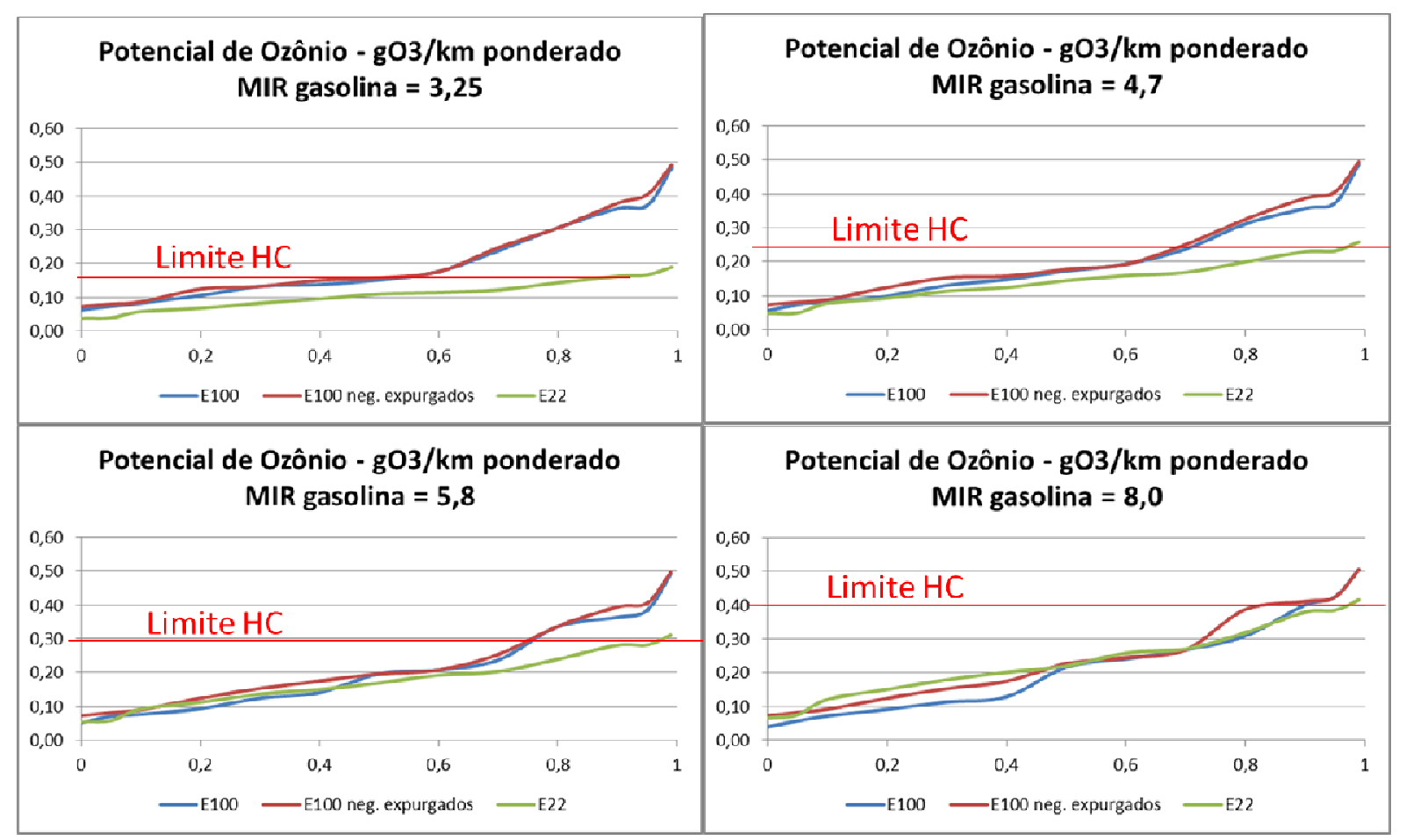

Figura 11 - Resultados estatísticos do potencial de ozônio para diversos valores de $\mathbf{M I R}_{\text {gasolina }}$ tomados como referência

Desta forma, os valores sugeridos pela Petrobrás não alterariam a estratégia de controle ambiental significativamente, embora isto não invalide a necessidade da 
determinação mais aprofundada do $M I R_{H C}$ de referência para a fração de "hidrocarbonetos puros" da emissão de compostos orgânicos.

Além disso, medições realizadas pela Volkswagen ${ }^{6}$ mostraram que a fração de hidrocarbonetos sem álcool e aldeídos produzidos pela queima de E100 também apresentam menores valores de MIR $\mathrm{NMHC}_{\mathrm{N}}$. Este fato justifica a preocupação de se determinar os valores de $\mathrm{MIR}_{\mathrm{NMHC} E 22}$ e MIR $\mathrm{RMHC}_{\mathrm{N} \text { E100para considerar a correção da }}$ reatividade também dos NMHC quando o motor funciona com etanol. Por outro lado, a correção da fração de NMHC utilizando E100 não é significativa porque esta emissão é a mais baixa, de forma que a adoção de um valor padrão é bastante aceitável.

Em termos do conceito de hidrocarboneto equivalente, é recomendável admitir o MIR $_{\text {NMHC_E22 }}$ (correspondente aos hidrocarbonetos gerados pela queima da gasolina comercial brasileira. Neste caso, o valor real correspondente a este combustível também deve ser comprovado, embora o valor 4,7 possa ser tomado como referência enquanto valores mais precisos não estejam disponíveis.

Complementarmente, os critérios de avaliação das emissões orgânicas ponderadas pelos respectivos MIR permitem avaliar também os combustíveis comerciais, para a discussão de estratégias que reduzam a formação de ozônio.

A figura 12 apresenta as curvas percentílicas dos hidrocarbonetos equivalentes, para os quatro valores de MIR $\mathrm{NMHC}_{\mathrm{N}}$ experimentados nestas simulações: os dois superiores correspondem à gasolina americana e ao cálculo mais provável da gasolina comercial brasileira, enquanto que os inferiores são os valores da gasolina da Califórnia e o da antiga gasolina brasileira.

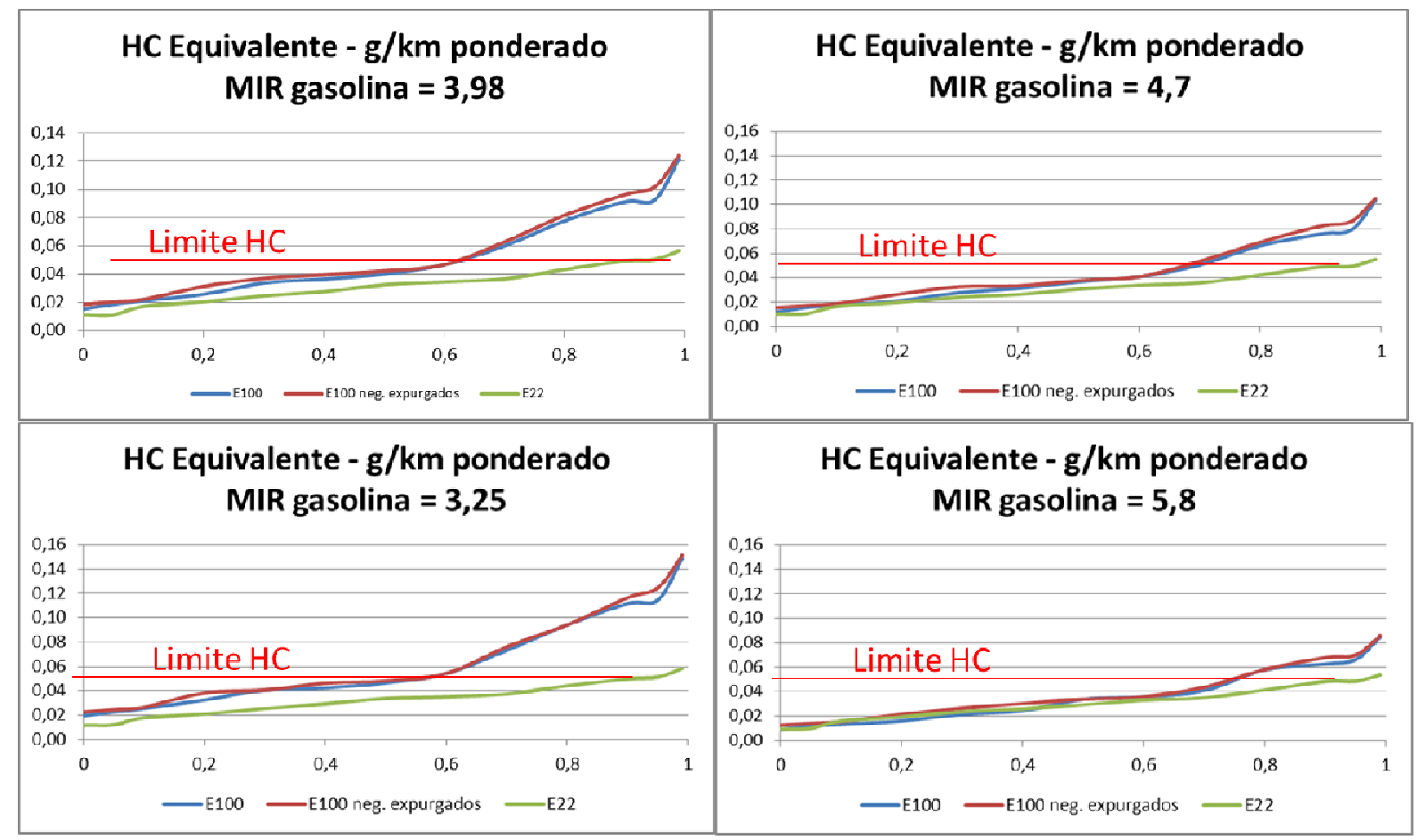

Figura 12 - Resultados estatísticos da emissão de $\mathrm{HC}_{\text {equivalente }}$ para diversos valores de $\mathbf{M I R} \mathbf{R}_{\text {gasolina }}$ tomados como referência 
A faixa de valores de $\mathrm{MIR}_{\mathrm{HC}}$ entre 4,0 e 4,7 indica que $35 \%$ a $40 \%$ dos motores flex deverão sofrer alterações para se enquadrarem nos limites de $\mathrm{HC}$ com o novo conceito de "HC equivalente em ozônio". Esta estatística também foi confirmada pela ANFAVEA ao repetir a mesma avaliação em 155 veículos de 7 fabricantes e, mais tarde, a CETESB encontrou as mesmas percentagens em 807 ensaios de certificação, contemplando 11 fabricantes, 9 sistemistas e 8 laboratórios de emissão de veículos ${ }^{7}$.

Adicionalmente, adotando-se o valor de 4,7 para o $\mathrm{MIR}_{\mathrm{NMHC}}$ nos cálculos dos veículos ensaiados neste exercício, o resultado final do MIR médio dos gases de escapamento obtido pelos potenciais de formação ozônio divididos pela correspondente emissão medida de NMHC do veículo funcionando com E22 variou de 3,4 a 3,95 com média de 3,71 e mediana de 3,75. Este resultado permite inferir que o valor de referência a ser recomendado não deve ser muito diferente dos que foram experimentados neste trabalho, sendo mais importante definir um valor de referência para dar início aos trabalhos de correção do problema dos veículos flex e depois aprimorá-lo se for necessário.

\section{Aplicação do conceito ao PROCONVE}

A aplicação do conceito do $\mathrm{HC}$ equivalente pode ser efetivada mediante a alteração do desconto do etanol, segundo os procedimentos de cálculo apresentados no capítulo 5 deste trabalho.

Embora pareça um processo complicado, para efeitos práticos pode-se simplifica-lo mediante a adoção de fatores MIR de referência, visto que a maior diferença e o problema de desconformidade dos veículos com o limite de HC avaliada pelo

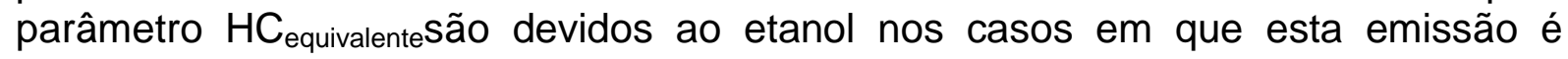
grande. Como, nestes casos, as concentrações de NMHC são pequenas comparadas às de etanol, as incertezas sobre os valores de MIR que multiplicam as concentrações de NMHC deixam de ser relevantes e a adoção de um valor padronizado torna-se recomendável para reduzir o custo e o trabalho de especiação de gases para o cálculo acurado da MIR específica para cada veículo.

De qualquer forma, as determinações de $\mathrm{HC}$ equivalente em ozônio devem ser procedidas no processo de certificação, com todos os detalhes necessários, mas a verificação de conformidade de emissões em veículos de produção poderá ser realizada apenas pelas medições de THC, uma vez que este parâmetro guarda boa correlação com os demais compostos orgânicos, desde que esteja devidamente correlacionado com a razão $\mathrm{THC} / \mathrm{HC}_{\text {equivalente }}$ para cada modelo, sendo estefator definido no processo de certificação.

Esta opção poderá economizar também as medições de aldeídos e etanol por cromatografia, economia que poderá ser melhor utilizada para aumentar o número de veículos ensaiados para o controle de produção. 


\section{Conclusões e Recomendações}

- A permissão do desconto do etanol induziu alguns projetos de motores flex atuais a priorizarem a injeção de etanol na partida a frio, elevando o potencial de formação de ozônio, quando o veículo flex trabalha com E100, visto que a emissão de etanol não queimado decorrente é sempre descontada;

- Tanto a média como a mediana dos potenciais de ozônio dos veículos flex estão compatíveis com o limite de $0,05 \mathrm{~g}$ de $\mathrm{HC} / \mathrm{km}$ para motores a gasolina, entretanto $35 \%$ dos modelos ensaiados ultrapassa esse limite quando utilizam E100;

- O parâmetro "NMHC com o desconto do etanof' não representa a emissão de compostos orgânicos dos veículos flex funcionando com álcool, enquanto que o THC guarda uma correlação com o resultado geral, tal como utilizado desde 1986 até 2004 pelo PROCONVE;

- Considerando os limites mais restritivos de HC, no estágio tecnológico atual, a emissão de ozônio baseada no THC seria superestimada em $60 \%$, sendo recomendável que a certificação de veículos considere as recomendações deste trabalho;

- A emissão exagerada de etanol por uma parcela significativa de veículos flex atuais leva esses veículos a apresentar maior potencial de contribuição para a formação de ozônio troposférico que outros veículos do mesmo tipo;

- A abordagem do controle da emissão de compostos orgânicos pelo escapamento de veículos com base no potencial de formação de ozônio é uma forma justa e equilibrada para a comparação de combustíveis alternativos sob a ótica ambiental. $\mathrm{O}$ conceito de $\mathrm{HC}_{\text {equivalente }}$ proposto neste trabalho considera todos os aspectos teóricos para o seu equacionamento e também sugere algumas simplificações possíveis para a sua implantação prática no PROCONVE, como a adoção de fatores de referência para as reatividades dos NMHC gerados por motores a gasolina, E22 e E100.

- Recomenda-se a correção do cálculo da emissão de hidrocarbonetos como $\mathrm{HC}_{\text {equivalente }} \mathrm{em}$ fases futuras do PROCONVE, para a padronização de estratégias de calibração e de tecnologias, baseando-se a evolução dos motores flex em tecnologias atualmente existentes e empregadas na maioria dos veículos, devendo-se manter $\mathrm{o}$ valor limite de $0,05 \mathrm{~g} / \mathrm{km}$ de $\mathrm{HC}_{\text {equivalente, }}$ compatível com as regulamentações internacionais.

- A aplicação do conceito de HC equivalente em ozônio como proposta neste trabalho é viável e pode ser implantada na próxima fase do PROCONVE. Enquanto não forem determinados valores experimentais acurados dos MIR dos $\mathrm{NMHC}$ para aprimorar os cálculos de $\mathrm{HC}_{\text {equivalente, }}$ propõe-se a adoção do valor MIR igual a 4,7 como referência para comparação das emissões de NMHC de veículos a gasolina;

- Será necessário aprimorar as medições por especiaçãodas emissões de compostos orgânicos e estudar a possibilidade de realizar a verificação de 
conformidade de emissões em veículos de produção apenas pela leitura de THC a ser correlacionada com o fator certificado de $\mathrm{THC} / \mathrm{HC}$ equivalente para cada modelo;

- É necessário revisitar os resultados de certificação de veículos desde a introdução do desconto do etanol para recalcular as emissões de compostos orgânicos e os respectivos potenciais de formação de ozônio, ou atribuir fatores de conversão para a revisão do inventário.

Controle de Emissão de Compostos Orgânicos com base no Potencial de Formação de Ozônio_SIMEA 2013 _Gabriel Branco_V2 revisada 9.6 .13

\section{Bibliografia}

${ }^{1}$ Andrade, M.de F.- Laboratório de Análise dos Processos Atmosféricos - LAPAt, Departamento de Ciências Atmosféricas, IAG USP - jun. 2006

${ }^{2}$ ANFAVEA - Desconto de Álcool Não Queimado - apresentação para o GTE Álcool Não Queimado em maio de 2012

3 Branco, G.M.; Branco, F.C.; Szwarc,A. - Considerações sobre as Medições de Compostos Orgânicos nos Motores Flex: Aplicação preliminar do conceito NMOG a resultados obtidos em veículos de produção segundo NBR 6601 - apresentação da EnvironMentality para o GTE Álcool Não Queimado emmarço de 2012

${ }^{4}$ Carter, W.P.L.- Updated Maximum Incremental Reactivity Scale and Hydrocarbon Bin Reactivities for Regulatory Applications - Prepared for California Air Resources Board - Revised January 28, 2010

${ }^{5}$ Cordeiro, T. - Mir da Gasolina Brasileira: Estudo Preliminar - apresentação da Petrobrás para o GTE Álcool Não Queimado em outubrode 2012

${ }^{6}$ Graner, L. - Determinação da reatividade dos hidrocarbonetos no gás de escapamento de um veículo Totalflex funcionando com E22 e E100 - Apresentação no GTE/AEA - Junho/2013

${ }^{7}$ Abrantes, R.; Sousa, R.B. - Determinação de Etanol Não Queimado - apresentação da CETESB para o GTE Álcool Não Queimado em agosto de 2012 